\title{
DE LA LUZ A LAS SOMBRAS: LOS JARDINES DE JOSÉ DONOSO Y ADOLFO COUVE ${ }^{1}$
}

\author{
From light to shadows: The gardens of José Donoso and Adolfo Couve
}

\author{
Sebastián Schoennenbeck Grohnert*
}

\section{RESUMEN}

Definido como una construcción cultural, el paisaje motiva un diálogo entre los narradores José Donoso y Adolfo Couve. Pese a sus diferencias, ambos tematizan la mirada ante el jardín para poner en crisis la descripción realista del espacio. Entre la luz y la oscuridad, entre la visión y la ceguera, la mirada afecta una descripción inicialmente icónica para luego registrar un desdibujado jardín en ruinas que pone en jaque las certezas de la modernidad.

Palabras clave: Jardín, paisaje, mirada, descripción, ruina.

\begin{abstract}
Defined as a cultural construction, landscape motivates the dialogue between writers José Donoso and Adolfo Couve. In spite of their differences, both of them thematize the look towards the garden to put in crisis the realistic description of space. Between
\end{abstract}

\footnotetext{
${ }^{1}$ Este artículo es resultado del Proyecto Fondecyt Regular N ${ }^{\circ} 1150050$ titulado "Muerte en el jardín: paisaje y heterotopía en la obra de José Donoso, Mauricio Wacquez y Adolfo Couve" que dirijo como investigador responsable.

* Director Departamento de Literatura, Facultad de Letras, Pontificia Universidad Católica de Chile. Santiago, Chile. Correo electrónico: sschoenn@uc.cl
}

Artículo recibido el 30 de mayo de 2017. Aceptado el 12 de diciembre de 2017. 
light and darkness, sight and blindness, the gaze modify an initially iconic description to register a blurred, ruined garden that puts in check the certainties of modernity.

Keywords: Garden, landscape, look, description, ruin.

No es fácil inventar un diálogo entre dos escritores chilenos aparentemente tan disímiles como lo son José Donoso (1924-1996) y Adolfo Couve (19401998). Aunque fueron contemporáneos, no sabemos si alguna vez se reunieron o si uno leyó al otro. Los diarios de José Donoso ${ }^{2}$ no mencionan al autor de $E l$ Picadero (1974). Al mismo tiempo, sus diferencias son evidentes. José Donoso se instaló dentro del canon de la literatura nacional. Adolfo Couve, en cambio, permaneció en los márgenes del campo cultural local, cultivando novelas breves $^{3}$. Su partida a Cartagena en 1983 fue tal vez una señal de abandono de una actividad cultural metropolitana. Mientras José Donoso especuló sobre su propia visibilidad en el fenómeno del boom ${ }^{4}$, Adolfo Couve, por el contrario, construyó una imagen de sí cuyo interés para el público radicaba en cierto aire de misterio que lo convirtió finalmente en una figura legendaria y de interés mediático ${ }^{5}$.

\footnotetext{
2 Donoso, José. Diarios tempranos. Donoso in progress, 1950-1965. Edición de Cecilia García-Huidobro. Santiago de Chile: Ediciones Universidad Diego Portales, 2016.

${ }^{3}$ Respecto a la extensión del relato de Couve titulado El cumpleaños del señor Balande, Adriana Valdés afirma lo siguiente: "Por jugar, sugiero que se trata de una novela contrahecha, de una novela enana. La miniaturización es un recurso de caricatura, carnavalesco en relación con el género: una forma de volver monstruoso el género de la gran novela burguesa, y sus cuadros de costumbres; una forma de poder echársela al bolsillo" ("Un duende y una novela: sobre una obra de Adolfo Couve", 184). Tal miniaturización es otra forma con la cual el mismo autor se desdice de su adhesión al realismo decimonónico.

${ }^{4}$ Ver Historia personal del boom de José Donoso.

${ }^{5}$ Adriana Valdés señala: “Adolfo Couve va en camino hacia su leyenda. A su alrededor se tejen y desatan fantasías de muchos tipos. Su bella figura, solitaria, contradictoria, frágil, mil veces fotografiada en su antigua casa sobre el mar; su trágico final; la exposición retrospectiva de su pintura en el Museo de Bellas Artes, el año pasado, contribuyen a mantenerlo presente en el imaginario colectivo. Temo que la brocha gorda de ese imaginario - cada vez más gorda, cada vez más basta y más mediática- termine por arrasar del todo con los muchos matices de su obra, para dejar apenas un ícono del "consumo cultural", como pasa en estos días con Frida Kahlo o con Virginia Woolf” (“Adolfo Couve, narrador de lo inquietante”, 7).
} 
Desde un punto de vista formal, Donoso optó por la experimentación, trascendiendo la tradición del criollismo $^{6}$. Sospechoso de las vanguardias, Couve, en cambio, se definió a sí mismo como un heredero de la escuela decimonónica francesa: "La escuela realista a la que adhiero, más que una porfía o lo que podría pensarse como un anacronismo, es en mí un sentir profundo" (Couve, "Prólogo" 7).

Pese a estas diferencias, las obras de ambos autores pueden ser comparadas con el objetivo de resignificar sus lecturas y relativizar sus posiciones en el campo cultural. Un primer rasgo en común es la resistencia ante una unívoca categorización gracias a la cual Donoso figuraría como voz experimental y Couve, como un realista. En efecto, el realismo irrumpe en la experimentación donosiana, aunque siempre lo hace al modo de una mascarada ${ }^{7}$. A su vez, las dos últimas novelas de Couve, La Comedia del Arte (1995) y Cuando pienso en mi falta de cabeza (2000), presentan un giro con respecto a la tradición que anteriormente cultivó. Según José Alberto de la Fuente, la última novela del autor es "es un relato mágico (que en cierto sentido contradice y pone en duda la consecuencia con la noción de realismo descriptivo)" (97). Por su parte, Felipe Toro también advierte cambios a lo largo de la producción del escritor:

Al revisar la obra narrativa de Adolfo Couve, rara avis del panorama de la novela chilena reciente, el lector experimenta una suerte de extravío, sobre todo al observar los cambios que sufren sus textos. ¿Qué se podría decir de sus primeros artefactos narrativos -habitados por hermosos niños como si se tratara de una calculada ensoñación- que hiciera suponer el

\footnotetext{
${ }^{6}$ En su ensayo Historia personal del boom, José Donoso expresa esta opción a modo de una pregunta que debió resolver: "En lo personal, se me planteaba el derrumbe de las reglas, y con ese derrumbe, la apertura de las posibilidades. ¿Cómo escribir, a quién dirigirme? ¿Tuvo razón Pablo Neruda cuando en una ocasión le dijo a mi mujer que yo debía escribir "la gran novela social de Chile”, porque nadie sentía "el frío de los pobres” como yo? ¿O tenían razón Fuentes, Cortázar, Sábato, Vargas Llosa, que señalaban no el camino de lo directo $-\mathrm{y}$ en ese sentido la frase de Neruda es el espaldarazo definitivo-, sino el peligroso camino de la experimentación. . ." (91-2)..

${ }^{7}$ Pienso, por ejemplo, en el trabajo de Leonidas Morales, quien lee Casa de Campo como una parodia del realismo. Ver “2. Máscara y enunciación”. Novela chilena contemporánea: José Donoso y Diamela Eltit. Santiago de Chile: Cuarto Propio, 2004.
} 
surgimiento de las Comedias, en donde el texto, paródicamente, parece avanzar hacia su propia disolución? (177-8).

Dado lo anterior, proponemos el jardín como un espacio en el cual ambos autores tematizan la mirada como fenómeno del paisaje. Según Javier Maderuelo, el paisaje no es la naturaleza ni tampoco el medio físico, sino más bien una construcción cultural. A través de la mirada, interpretamos y representamos el entorno. Es decir, el espacio y la naturaleza devienen imágenes y signos: “... la idea de paisaje no se encuentra tanto en el objeto que se contempla como en la mirada de quien contempla. No es lo que está delante sino lo que se ve" (38) Ahora bien, la descripción del jardín en la obra de J. Donoso y A. Couve oscila entre un apego al realismo ${ }^{8}$ y una indeterminación que lo oscurece, poniendo en jaque la visión del paisaje. Es decir, el jardín está sujeto paradójicamente a una representación que lo expone ante la mirada del sujeto, pero también ante una palabra que entorpece el tránsito ocular ${ }^{9}$. Este ejercicio paisajístico inventa un espacio donde se es visionario y ciego a la vez; un espacio donde lo canónico y lo marginal, lo experimental y lo tradicional, lo local y lo cosmopolita se encuentran y se alteran.

Ya la primera novela de José Donoso, Coronación (1957), inaugura este jardín que transita desde lo luminoso a lo lúgubre. Si bien con esta obra el autor aun no propone una escritura del todo experimental, la descripción final del jardín profetiza la muerte del realismo en la poética donosiana. Adornado con

\footnotetext{
${ }^{8}$ Para René Wellek, el realismo se define como "la representación objetiva de la realidad social contemporánea" (181). Según este autor, en el realismo, "se rechaza lo fantástico, lo que se asemeja a un cuento de hadas, lo alegórico y lo simbólico, lo altamente estilizado, lo puramente abstracto y decorativo. Implica también un rechazo de lo improbable, del puro azar y de los recursos extraordinarios" (182). El realismo, por lo tanto, construye "un mundo de causa y efecto" (182), dando lugar al "ordenado mundo de la ciencia" (182). También entenderemos por descripción realista aquella que genera un efecto visual; como si el lector estuviese viendo el objeto referido, esta descripción contará con recursos icónicos.

9 Victor Stoichita, en su obra Ver y no ver. La tematización de la mirada en la pintura impresionista, hablará de una "obstaculización de la mirada" (23) al analizar aquellos elementos representados pictóricamente que se interponen entre el personaje o espectador que mira y el objeto que se pretende registrar visualmente.
} 
dos palmeras, este espacio se describe como un "jardín desfalleciente" (250), pero que tuvo tiempos gloriosos cuando los tallos de los rosales de pie alto se pintaban de blanco. Aquel lugar que vemos inicialmente con total nitidez, pese a su deterioro, será descrito finalmente como una violenta selva enmarañada. El narrador proyectará la oscuridad nocturna para entorpecer nuestra mirada, generando un espacio del cual solo sospechamos. Se trata de un jardín que no se ve y, por lo tanto, no se le puede describir. En este "jardín turbio de lluvia" (242), los ladrones se esconderán para espiar el iluminado interior de la casa señorial. De ser un lugar de siesta y descanso, el jardín oscuro deviene escenario de violencia donde una muchacha es golpeada brutalmente.

En la obra narrativa de Couve, la descripción de un objeto se forja gracias a recursos visuales como, por ejemplo, la luz, la sombra, el color y el dibujo: "Al tiempo que el alba calcaba su rostro sobre la superficie del estero, rescatando de las sombras sus contornos, Elvira y su hijo se dirigían a la droguería" (La lección de pintura, 184). Sin embargo, el espacio sufre a veces de una oscuridad cuyo efecto es la desaparición del mismo objeto ante la mirada que intenta registrarlo. Esta borradura no se da solo en sus dos últimas novelas que desdicen el realismo cultivado anteriormente: "La bóveda infinita extendía ante sus ojos miríadas de estrellas. Los techos de las casas, los edificios importantes, la plaza, los árboles oscuros y el puente sobre el estero que se deslizaba a escondidas, habían perdido el volumen y, así esa ciudad plana daba la impresión de una lámina para un cuento de hadas" (El tren de cuerda, 121). Este paisaje urbano se construye al reconocer en la ciudad un artificio pictórico ("la ilustración de un cuento de hadas") ${ }^{10}$. Sin embargo, la mirada, recurso indispensable para la constitución del paisaje, es puesta en juego por la noche

\footnotetext{
${ }^{10}$ Según Alain Roger, se construye paisaje cuando el sujeto reconoce en el paraje que mira una imagen visual registrada en su memoria o acervo o cultural: "Considero que toda nuestra experiencia, visual y no visual, está más o menos moldeada por modelos artísticos” (67).
} 
que no permite ver el volumen de las cosas. Consecuentemente, la perspectiva visual se suspende y el mundo se vuelve una plana realidad. Este motivo tan característico de Couve vuelve a repetirse en la descripción de un parque: "El amanecer remoza los lugares y, sin embargo, es la hora del ocaso la más bella. Cleopatra permanecía horas interminables ante el espectáculo del atardecer, y percibía la dimensión distinta que adquirían los árboles al perder su volumen con la ausencia de luz..." (El parque, 165). Al ser eliminados los datos con respecto al volumen y al color, la descripción paisajística padece de una indeterminación que afecta la esencia de todo jardín. En suma, lo paradójico del paisaje radica en presentar el jardín en el momento en el cual la mirada testimonial lo registra como una inexistencia de belleza inconmensurable.

\section{Jardines bajo la luz}

Definida como “expansión textual” (Pimentel, 37), la descripción particulariza altamente al objeto y garantiza verosimilitud e inteligibilidad gracias a un sistema de contigüidades obligadas (59) y a la iconización. La descripción de un jardín despliega las unidades léxicas inherentes al objeto: pasto, prado, árboles, arbustos, flores, senderos, escaños, fuentes, macizos, espejos de agua, esculturas, lagunas, cascadas artificiales, glorietas, miradores, setos, etc. Por lo tanto, la descripción se organiza por medio de la inclusión, exclusión y restricción de unidades de significación en la medida que guardan, respectivamente, una relación de pertinencia o impertinencia al sistema. De este modo, un texto de ficción genera una ilusión de realidad cuando describe e identifica con nombre propio, por ejemplo, una ciudad o un jardín sin referente extratextual, porque utiliza un léxico y un sistema de contigüidades al cual obligatoriamente aludimos cuando describimos ciudades o jardines reales. $\mathrm{El}$ París y el Combray de Proust, por ejemplo, tienen el mismo estatuto diegético aunque uno sea real y el otro no. 
Otro rasgo descriptivo compartido por ambos autores es, en palabras de Greimas, la iconización ${ }^{11}$ del lenguaje. ¿Cómo un artefacto verbal puede estar asociado a una imagen visual? Desde la semiótica, Luz Aurora Pimentel indica que la iconicidad descriptiva radica en el poder de producir una ilusión de lo visual:

Cuando se habla de una imagen asociada con ciertos elementos lingüísticos y discursivos, se trata más bien de describir un efecto de sentido que se asemeja a una impresión de lo visual, impresión de la que están desprovistos lexemas como bondad o precisión. Pero ¿cómo es que se produce esta impresión de lo visual con medios no visuales como lo es el lenguaje? Aquí el concepto de iconización verbal nos puede ser útil para explicar ese efecto de realidad, o, más bien, ese efecto de lo sensorial que tienen algunos lexemas, el nombre común y el adjetivo de manera muy especial (34).

En la descripción paisajística, el color, el volumen, la cantidad y la distribución de los elementos que componen un jardín son también recursos de particularización icónica. Estas cuatro variables nos recuerdan aquellas con las cuales Foucault describe la observación del objeto de la Historia Natural: "forma de los elementos, cantidad de esos elementos, manera en que se distribuyen en el espacio los unos con relación a los otros, magnitud relativa de cada uno" (Las palabras y las cosas, 135).

Las determinaciones de una descripción paisajística con alto valor icónico corresponden también a principios inherentes a la composición de un jardín ${ }^{12}$. En efecto, color, volumen, distribución y cantidad son variables que se actualizan tanto en una descripción verbal como en una "real" composición

\footnotetext{
${ }^{11}$ Greimas, Julien. "Pour une sémiologie topologique”. Sémiotique de l'espace. Paris: Gonthier, 1979. La versión española, "Para una semiótica topológica" se encuentra en Semiótica y ciencias sociales. Traducción de Adolfo Arias Muñoz. Madrid: Fragua, 1980.

12 Jens Andermann identifica, por ejemplo, usos composicionales cromáticos y volumétricos en Roberto Burle Marx: "el descubrimiento simultáneo del arte moderno y de la flora tropical permitió a Burle Marx dar un paso más allá del uso puntillista de los ciclos florales y bordes mixtos empleados por Jekyll hacia un uso volumétrico de los valores cromáticos y texturales de sus característicos canteros monovegetales" (214).
} 
paisajística. De este modo, la descripción es como una re-composición o un reflejo retroactivo del proceso de construcción jardinera. Si bien no se trata de un recurso icónico, la determinación botánica también es un recurso de composición de paisaje y de descripción verbal. Donoso se afana en reconocer especies: "Salieron a la terraza, desde donde vieron la extensión lujosa del prado, la piscina, los quitasoles, los olmos, magnolios, araucarias y eucaliptos del parque..." (El obsceno pájaro de la noche, 502) En Couve, un personaje realiza el mismo ejercicio al mirar su jardín: "Luego desvió los anteojos e hizo, como acostumbraba, un minucioso inventario del lugar, comenzando por los rosales recién abonados, los lirios que bordeaban la pandereta..." (El tren de cuerda, 109).

La inteligibilidad de una descripción espacial también descansa en un complejo referencial que somete al texto a múltiples relaciones: "toda lectura que privilegia significados, por encima de los significantes, tiende a ser una lectura referencial. Un complejo referencial puede ser de cuatro tipos: extratextual, intertextual, intratextual y metatextual; es en el juego de todas estas direcciones referenciales que se construye la significación de un texto" (Pimentel, 112). Considerando el corpus de estudio, la referencia extratextual participa en el proceso de iconización a través de la ecfrasis. Definida como un género descriptivo que da cuenta de un objeto plástico sea real o no, la ecfrasis es "un juego en el que el texto define su identidad frente a ese otro que no es él" (113).

La abundancia de ecfrasis en la obra donosiana se explica, en parte, porque la pintura se presenta como una referencia capaz de concentrar el devenir narrativo. En otras palabras, la pintura es un motivo, porque establece estructuralmente una relación con todos los otros elementos del texto. Se trata entonces de un esquema que se repite y que puede ser formulado de múltiples maneras. Por ejemplo, en la novela póstuma La lagartija sin cola (2008), el protagonista es un pintor que reflexiona constantemente sobre su oficio. Átomo 
verde número cinco (1973), Naturaleza muerta con cachimba (1990) y El jardín de al lado (1981), entre otros, son relatos en los cuales se presenta el robo de un cuadro. Este motivo da lugar a descripciones directas de una pintura gravitante en el mundo narrativo. A su vez, la identificación de personajes se produce a través de referencias pictóricas o escultóricas que el texto no tarda en caracterizar. En El jardín de al lado, por ejemplo, “[e]l fenómeno es patente en la designación recurrente de los personajes por sobrenombres inspirados por el mundo de la pintura. La odalisca para Gloria, las figuras filiformes de Brancusi o abigarradas de Klimt para Monika Pinell de Bray, el angelo musicante para Bijou" (Dejong, 314) En Casa de campo (1979), José Donoso ha transportado el cuadro de Watteau, Embarquement pour Cythère, desde el Museo de Louvre a la casa de los Ventura. Con esta referencia pictórica se describe el supuesto paseo campestre de los Ventura si fuese una fiesta galante, género pictórico con el cual se identifica el título de Watteau.

En la obra de Couve, las ecfrasis son frecuentes, porque muchos de sus títulos, La lección de pintura (1979), El tren de cuerda (1976), entre otros, giran en torno al oficio de un pintor muchas veces degradado ${ }^{13}$. En clave paródica la mayoría de las veces, las ecfrasis de Adolfo Couve son introducidas por citas a pinturas en particular o por la mención a grandes maestros. Sin embargo, no se trata solo de pinturas históricamente identificables, sino también de obras ficticias: el narrador dará cuenta de la producción de los personajes pintores tales como Camondo y Sandro en La comedia del arte y Cuando pienso en mi falta de cabeza. En estos casos, la ecfrasis no supone una referencia

\footnotetext{
${ }^{13}$ Respecto a la novela de Couve titulada La Comedia del Arte, Adriana Valdés afirma: "Es interesante que La comedia del arte tenga por tema también una farsa, una versión grotesca del duelo por lo sublime: el duelo por lo sublime pictórico, parodiado en forma sangrienta por la narración. La modelo dada de baja, mientras posa, desgrana porotos en el casco de Afrodita. Las convenciones de una pintura, encarnadas en Camondo como paisajista, llegan al total fracaso, al "circuito estéril", a la renuncia; y el sujeto pintor, Camondo mismo, a la "copia inanimada, fría y perfecta" de sí mismo en una figura de cera (motivo este también propio del grotesco)" ("Prólogo", 19).
} 
extratextual, sino intratextual. En suma, la obra de Adolfo Couve expone, al modo de una galería irónica, una diversidad de géneros que van desde el retrato y el paisaje a la naturaleza muerta. En El picadero (1974), se describe el retrato de un antepasado de la familia Sousa que decora las paredes del comedor: "Antes de solucionar el enigma, sus ojos encontraban la respuesta en la mirada al óleo que le dirigía Zapiola. Su rostro parecía más fiero que nunca, enmarcado en esa ridícula peluca” (75). En El tren de cuerda, el jardín, básicamente un patio trasero sembrado de amapolas, será descrito como el organismo al cual se enfrenta un pintor aficionado que intenta un paisaje in situ. Es decir, se lo describe presentando el paisaje pictórico que lo registra: "ese aroma dulzón le recordó aquel otro que despedían las flores al óleo que este solía pintar en el jardín" (128).

La referencia extratextual también puede ser identificada en la operatividad de modelos culturales suplementarios que provienen "de otros discursos del saber oficial o popular, tales como el de los sentidos, taxonomías científicas o populares, modelos de organización urbana, o provenientes de otras artes (arquitectura, pintura, música)" (Pimentel, 63). En el caso de las descripciones de los jardines de José Donoso y Adolfo Couve, el modelo extratextual, fuente que garantiza verosimilitud y realismo, está dado por la referencia no explícita al discurso de un saber, de una disciplina y de un oficio que finalmente guarda relación con el archivo de la arquitectura del paisaje en Chile ${ }^{14}$.

¿Cuál es el archivo que posibilita la descripción paisajística en Donoso y Couve? El modelo de jardín que opera como referente extratextual en ambos autores corresponde básicamente al de la segunda mitad del siglo XIX y

\footnotetext{
${ }^{14}$ El archivo paisajístico no es solo un conjunto de documentos custodiados que registran la construcción, permanencia o destrucción de parques y jardines. Se trata más bien de una experiencia histórica que posibilita a un sujeto describir de cierta manera y no de otra el espacio que aquí nos interesa. Según M. Foucault, "el archivo es primer lugar la ley de lo que puede ser dicho, el sistema que rige la aparición de los enunciados como acontecimientos singulares" (La arqueología del saber, 219).
} 
primeros años del siglo XX. Que el jardín en los imaginarios de Donoso y Couve se module con una fuerte marca de clase se explica, en parte, gracias a esta relación con un proyecto histórico de arquitectura de paisaje gestado por las élites. En efecto, hombres de grandes fortunas mineras materializan sus nuevas posiciones en viviendas y áreas verdes privadas: "Pero será solamente en la tercera y cuarta década del siglo XIX cuando nace el gusto por los grandes parques de tipo romántico, comenzando con aquel que Mariano Egaña proyectó en Peñalolén" (Trebbi, 17). El afán extranjerizante de estos proyectos obliga a la contratación de paisajistas extranjeros. El francés Guillermo Renner diseña el parque de la Viña Santa Rita, el parque de Las Majadas de Pirque, el parque Cousiño Macul y el Parque O’Higgins de Santiago. En 1896, Renner arboriza por primera vez la Plaza de Armas de la capital. Contemporáneo a Renner, Georges Dubois traza el Parque Forestal y el parque de la hacienda La Punta, al norte de Rancagua. Entre 1862 y 1873, el paisajista inglés Bartlet, contratado por Luis Cousiño, construye el parque Lota, cuyo diseño original será posteriormente ampliado y modificado por el irlandés Guillermo O'Reilly bajo la supervisión de Isidora Goyenechea. Finalmente, el italiano Cánova es contratado por Carlos Valdés Izquierdo en 1873 para diseñar los jardines y parques de la hacienda de Cunaco, en la provincia de Colchagua. Los espacios de Renner, Dubois y Cánova continúan la tradición de Jean-Pierre BarilletDeschamps, paisajista que proyectó el Bois de Boulogne bajo la revolución urbanística de Haussman. Estamos ante un paisaje que combina claros o extensiones libres sembradas de pasto con bosques espesos que tienden a lo selvático. Entre grandes avenidas, múltiples senderos peatonales serpentean sobre la superficie. Estas áreas verdes, por lo tanto, no solo se miran, sino también se recorren. Una prolífera ornamentación escultural y acuática detona una infinidad de sorpresas que atacan al caminante una vez que ha superado la curva de un sendero o ascendido o descendido una escalinata. Son parques en el que el caminante podría perderse. Por lo tanto, este modelo paisajístico se 
apropia de ciertas usanzas del jardín manierista, el cual expulsó la huerta del antiguo jardín renacentista, relativizó su centro homogeneizador y tendió hacia la ornamentación no vegetativa ${ }^{15}$.

Los parques descritos por José Donoso y Adolfo Couve también tendrían a la Quinta Normal como referente de paisaje para la constitución del espacio ficcional. Inaugurada bajo el gobierno de Bulnes, la Quinta Normal no fue planificada a partir de criterios paisajísticos, sino agronómicos. Era el espacio donde se experimentaba con cultivos y se aclimataban especies exóticas. Según el arquitecto Teodoro Fernández, la Quinta Normal es la matriz de aquellos parques que rodean las casas patronales del Valle Central de Chile y que podremos reconocer con frecuencia en las obras de Donoso y Couve. Se trata de superficies con una densa población arbórea que impide vistas panorámicas desde la vivienda. Pese a sus amplias extensiones, son jardines autorreferentes y no responden siempre a planificaciones profesionales: "En medio de todo este caos, y bajo el único claro que permitían los enormes paltos, había una pila de cemento" (Couve, Una lección de pintura, 136).

Sin embargo, otras descripciones de paisaje se caracterizan por una estilización, ya que contienen una alta densidad de citas y referencias culturales. En efecto, el parque de los Ventura en Casa de Campo de José Donoso es visualizado como un paisaje ideal de Poussin. Sus dueños reconocen en su combinación cromática una pintura de Corot. Su frondosidad nos recuerda el verdor de la pintura de Watteau así como sus "personajes bergamascos", el poema "Claro de Luna" con el cual Verlaine da inicio a Fiestas Galantes:

\footnotetext{
${ }^{15}$ En Spazio e allegoria nel giardino manierista, Fausto Testa afirma: "La vicenda dell' arte in Italia nel corso del '500 declina, in una serie di esperienza plurime e contraddittorie, la crisi in cui si problematizzano, fino a dissolversi, gli ideali estetici del rinacimento. Teso nella ambigua dialettica tra infrazione anticlassica e classicismo accademico, tra naturalismo e formalismo, el manierismo vive il depauperarsi della fede rinascimentale nel valore cognitivo dell' esperienza artistica, fondato sulla riconosciuta contigüitá tra arte e natura" (16).
} 
Su parque de castaños, tilos y olmos, sus amplios céspedes por donde deambulaban los pavos reales, la diminuta isla de rocaille en el laghetto de aguas pobladas por papiros y nenúfares, el laberinto de boj, el rosedal, el teatro de verdura poblado de personajes bergamascos, las escalinatas, las ninfas de mármol, las ánforas, remedaban sólo los modelos más exaltados, desterrando toda nota que lo comprometiera con lo autóctono $(62-3)$.

En la novela El Picadero de Adolfo Couve, las avenidas de castaños, los salones y las caballerizas de Villacler nos hacen pensar más en un chateau auténticamente francés que en una modesta versión sudamericana. El espacio recibe un tratamiento descriptivo extranjerizante y cosmopolita hasta el punto que se torna exótico para un lector chileno. Esta nouvelle recrea una belle epoque que, por muy criolla que sea, se la sitúa en un pasado ya tan remoto que se vuelve una fantasía o uno de esos lugares que sufren la indeterminación del "había una vez" o "érase una vez" de los cuentos de hadas. Al igual que Casa de campo, la espacialidad de este relato de Couve no es determinada geográficamente. En suma, estas referencias culturales con las cuales se describe y se compara el espacio dan lugar a un paisaje estilizado que se aleja del parque más rudimentario que registra el archivo.

La histórica intervención paisajística en Chile figura como un referente extratextual que posibilita las descripciones realistas de los jardines y parques. No obstante, ambos autores también alteran el modelo extratextual, es decir, el modelo disciplinario, dando lugar a una crisis descriptiva. Poner en jaque el archivo del paisaje pone de relieve el carácter artificial de la descripción, rompe la naturalización a la que hemos sometido nuestros modos de ver el mundo y revela que la percepción de un objeto real es, incluso antes de la escritura, una percepción semiotizante. Los modos de manipulación del archivo paisajístico chileno serán principalmente la parodia, la inversión y la degradación. Sin embargo, estos discursos y efectos son posibles en la medida que se hace abandono de los recursos icónicos de composición descriptiva para presentar 
un jardín como un campo de sombras sujeto, muchas veces, a una irrupción de oscuridad nocturna. El jardín se vuelve entonces una mancha ininteligible ya liberada de la identificación figurativa. En este movimiento oscilante entre luz y sombra, el jardín trastornado revela su rostro detenidamente dibujado para luego ser cubierto por un velo que entorpece la mirada de lector.

\section{Jardines de sombras}

¿Cómo se ensombrece descriptivamente un jardín hasta el punto de hacer de su visión una imposibilidad? ¿cómo el paisaje que transforma el jardín en imagen se aleja del realismo descriptivo al que fueron vinculados en primera instancia de esta reflexión las obras de José Donoso y de Adolfo Couve? En el caso del primero, lo primero que salta a la vista es el cultivo de la alegoría: en Casa de campo, el código realista se subvierte cuando la novela nos da las claves para una lectura alegórica ${ }^{16}$. En Couve, la parodia y el arquetipo a lo Comedia dell'Arte participan en procedimientos irreverentes ante el mismo realismo al cual el autor declara adherir. Sin embargo, el grotesco es un recurso de oscurecimiento común a ambos autores. Si bien la ornamentación grotesca forma parte de algunas tradiciones paisajísticas tales como el manierismo, el complejo escultórico que adorna los patios de la Rinconada en El Obsceno pájaro de la noche padece un efecto grotesco que le es originalmente ajeno. En efecto, los dioses clásicos ya no serán esculpidos a la luz de lo bello: “Adornó los demás patios con otros monstruos de piedra: El Apolo desnudo fue concebido como retrato del cuerpo jorobado y las facciones del futuro Boy adolescente, la nariz y la mandíbula de gárgola, las orejas asimétricas, el labio leporino, los brazos contrahechos y el descomunal sexo colgante que desde la cuna arrancó

\footnotetext{
${ }^{16}$ Ver Cerda, Carlos. José Donoso: originales y metáforas. Santiago de Chile: Planeta, 1988.
} 
ohs y ahs de admiración a las enfermeras" (241).

En Couve, la pintura académica, cuyos paisajes pretendieron dar cuenta de una "esencia chilena" ${ }^{17}$, es citada recurrentemente, pero de manera degradada. En El tren de cuerda, por ejemplo, el chófer que pinta un paisaje in situ en el patio trasero de la casa de sus patrones es desenmascarado y se revelará como un travesti grotesco. Escenario en el cual se suspende el orden de la naturaleza, el jardín grotesco funciona al modo de una pieza oscura donde el sujeto juega y se extravía. "El mundo de este arte ornamental ya no está cerrado sino que constituye el fondo oscuro y siniestro de un mundo más claro y rigurosamente ordenado lo cual es, en rigor, una imitación de los hallazgos en las grutas)" (Kayser, 19-20).

El debilitamiento de la descripción realista en torno al jardín también puede ser explicado a través de la abstracción. La identificación de un objeto que compone el espacio es reemplazada por la determinación tan solo de su color o de una forma geométrica que lo sintetiza. La vegetación que ornamenta los patios de la Rinconada monstruosa en El obsceno pájaro de la noche ya no estará sujeta a una nomenclatura botánica. En efecto, los arbustos serán presentados a través de su volumen adquirido por efecto del arte topiario:

La mansión quedó convertida en una cáscara hueca y sellada compuesta de una serie de estancias despobladas, de corredores y pasadizos, en un limbo de muros abierto hacia el interior de los patios de donde ordenó arrancar los clásicos naranjos de frutos de oro, las buganvillas, las hortensias azules, las hileras de lirios, reemplazándolos por matorrales podados en estrictas formas geométricas que disfrazaran su exuberancia natural (p. 240).

\footnotetext{
${ }_{17}$ Se trata de aquellos pintores nacionales formados bajo los preceptos de la Academia de Pintura fundada en 1849, pero que finalmente encuentran sus propios caminos de libertad en el paisaje: "El pintor chileno, que había tenido que mirar hacia un mundo alejado, impuesto por la autoridad de los directores extranjeros de la Academia y por las propias condiciones del devenir histórico nacional, pudo ahora reencontrarse; aunque no con su historia precisamente, pero por lo menos con su tierra: el cielo, el océano, la montaña, el campo chilenos serán, en adelante, su refugio. El paisaje autóctono dejará de ser el gran olvidado" (Ivelic-Galaz, 94).
} 
En El jardín de al lado, los objetos pierden sus contornos; se transforman así en manchas, imposibilitándonos una identificación "realista": "La realidad que rodea al narrador no se describe como un conjunto de objetos o paisajes sino como una sucesión de formas geométricas: un macizo de flores se transforma en un "polígono de suculentas" o en "manchas de caléndulas" (Dejong, 313). Este proceso de abstracción promueve una autonomía del paisaje con respecto a la imitación mimética de la naturaleza y garantiza una "liberación absoluta del espacio ficticio, que proclama su autonomía" (Gutiérrez Mouat, 146).

En Couve, el paisaje se desdibuja por efecto de las lágrimas que entorpecen la mirada ocular, generando una alteración formal del objeto. En El pasaje (1989), una marina será sometida a este proceso de momentánea indeterminación:

Lejos, en el horizonte, una embarcación se ladeaba hasta casi rozar con sus velas el mar. Parecía que era la intensa luminosidad y no el viento que lo hacía inclinarse de aquel modo. Disimulando la pena que le causaba esa situación, Rogelio se resistía a despegar la vista de la pequeña goleta, la que, a pesar de que él trataba de impedirlo, se desdibujó, volviendo a su anterior nitidez luego que al niño le rodaran dos lágrimas por las mejillas (247).

\section{Conclusiones}

Estos jardines visitados son presentados como ruinas. En el relato $E l$ parque de Couve, el equilibrio entre espíritu y materia se rompe (Simmel, 40). El jardín, artificio humano, "aparece como un producto de la naturaleza" (43) que desborda sus límites ${ }^{18}$. Afectas al paso del tiempo y al clima, las esculturas

\footnotetext{
${ }^{18}$ Según Nicolás Rubio y Tudurí, "en lengua persa, gird, gardar, orígenes de nuestra voz “jardín”, responden conjuntamente a la noción de círculo y de cercado; provienen de gardinam, estar rodeado de" (51). El mismo José Donoso indica: "Un jardín es, por definición, un espacio limitado, un hortus conclusus artificial, cuyo orden se debe a las leyes de la fantasía: una creación esencialmente separada y distinta a la naturaleza que rodea a ese espacio" (“Algo sobre jardines”, 129).
} 
del parque señalan su deterioro evidente: "De este modo, el parque integró a sus habitantes inmóviles, aun cuando para lograrlo le fue necesario partir en dos algunas ánforas, decapitar una Venus, trizar al fauno de hierro o asediar de enredaderas y follaje al resto" (El parque, 164). En Donoso, el parque de Casa de campo será comparado con las ruinas pintorescas de Hubert Robert y Salvatore Rosa.

El jardín en ruinas imprime un carácter alegórico al texto que lo alberga, puesto que la alegoría transita pendularmente entre lo visual y lo verbal y, al mismo tiempo, establece una analogía con la ruina: "Las alegorías son en el reino de los pensamientos lo que las ruinas en el reino de las cosas" (Benjamin, 180) ¿Qué nueva significación logran los textos analizados al ser leídos como alegorías? El jardín descrito en ruinas podría ser alegoría de una historia no progresiva, un decir que niega una proyección utópica, porque este espacio verde, cita, al modo de una heterotopía, otros espacios, espacios vinculados a las bellas artes, al orden familiar y al orden nacional con el amague de degradarlos e incluso invertirlos. Dado lo anterior, el jardín no siempre es un paraíso así como lo fue el bíblico Jardín del Edén.

Según Andreas Huyssen, la ruina despierta la nostalgia por un pasado que se presenta fragmentaria y residualmente, delatando "las trágicas debilidades del presente" ( 38 ) En efecto, el pasado que se añora nostálgicamente correspondería al de una joven modernidad que prometía diferentes futuros. Nostalgia por una utopía que solo se visualiza como ruina, ausencia y pasado en descomposición, la mirada paisajística de Donoso y Couve ante un jardín señala "una constelación significativa tanto conceptual como arquitectónica que apunta a momentos de decadencia y disgregación ya presentes en los comienzos de la modernidad (39). En oposición a las nociones lineales y triunfalistas del progreso, los efectos nostálgicos de la ruina develan "el lado oscuro de la modernidad" ( 43) y nos recuerdan "que toda historia puede finalmente ser aplastada por la naturaleza" (44). Entre la tradición del realismo y la ruina 
alegórica, el jardín es aquel espacio en el cual la mirada del sujeto se desplaza desde una luz que permite identificar los contornos y formas del paisaje a una oscuridad enceguecedora.

\section{Referencias}

Andermann, Jens. "Cosmopolitismos telúricos: jardín y modernidad en Latinoamérica". Revista de crítica Literaria Latinoamericana 79 (2014): 201-225.

Benjamin, Walter. El origen del Trauerspiel alemán. Trad. Alfredo Brotons. Madrid: Abada, 2012.

Couve, Adolfo. "Prólogo". Cuarteto de la infancia. Argentina: Seix Barral, 1996: 7-10.

----------. "La lección de pintura". Narrativa Completa. Santiago de Chile: Seix Barral, 2003: 171-207.

----------. "El tren de cuerda". Narrativa Completa. Santiago de Chile: Seix Barral, 2003: 107-152.

----. "EL parque". Narrativa Completa. Santiago: Seix Barral, 2003:153-169. . "El pasaje". Narrativa Completa. Santiago: Seix Barral, 2003: 209-249.

Dejong, Nadine."Arte narrativo y arte pictórico en El jardín de al lado de José Donoso". Actas del XIII Congreso de la Asociación Internacional de Hispanistas Tomo IV. Ed. Florencio Sevilla y Carlos Alvar. Madrid: Castalia, 2000: 309-317.

Donoso, José. Historia personal del boom. Santiago de Chile: Alfaguara, 1998. ----------. El obsceno pájaro de la noche. Santiago de Chile: Alfaguara, 1998. . Coronación. Chile: Alfagura, 2016.

-----------. Casa de campo. Santiago de Chile: Alfaguara, 1999. "Algo sobre jardines". Artículos de incierta necesidad. Ed.

Cecilia García-Huidobro. Santiago de Chile: Alfaguara, 1998:129-137.

Foucault, M. La arqueología del saber. Trad. Aurelio Garzón del Camino. México: Siglo XXI, 1979. 
Fuente, José Alberto de la. "Identidad y realismo en la narrativa de Adolfo Couve". Literatura y Lingüistica 13 (2001-2002): 89-104. - Las palabras y las cosas. Una arqueología de las ciencias humanas. Traducción de Elsa Cecilia Frost. México: Siglo XXI, 2005.

Gutiérrez Mouat, Ricardo. "El obsceno pájaro de la noche: la Historia y las historias". José Donoso: impostura e impostación. U.S.A: Hispamérica, s/a. impreso.145-195.

Huyssen, Andreas. "La nostalgia por las ruinas". Heterocronías. Tiempo, arte $y$ arqueologías del presente. Traducció María Velásquez. Ed. Miguel Hernández Navarro. Murcia: CENDEAC, 2008: 35-56.

Ivelic, Milan y Galaz, Gaspar. La pintura en Chile. Desde la Colonia hasta 1981. Chile: Ediciones Universitarias de Valparaíso, 2009.

Kayser, Wolfgang. Lo grotesco. Su configuración en pintura y literatura. Trad. Ilse M. de Brugger. Buenos Aires: Editorial Nova, 1964. Impreso.

Maderuelo, Javier. "1. La definición de paisaje”. El paisaje. Génesis de un concepto. Madrid: Abada, 2006: 15-39.

Pimentel, Luz Aurora. El espacio en la ficción. La representación del espacio en los textos narrativos. México: Siglo XXI, 2010.

Roger, Alain. "vida y muerte de los paisajes. Valores estético, valores eco lógicos". El paisaje en la cultura contemporánea. Ed. Joan Nogue. Madrid: Biblioteca Nueva, 2008: 67-85.

Rubió y Tudurí, Nicolás. Del paraíso al jardín latino: origen y formación del moderno jardín latino. Barcelona: Tusquets, 1981.

Simmel, George. "Las ruinas". Filosofia del paisaje. España: Casimiro, 2013: 39-50.

Stoichita, Victor. Ver y no ver. La tematización de la mirada en la pintura impresionista. Trad. Anna María Coderch. España: Siruela, 2005.

Testa, Fausto. Spazio e allegoria nel giardino manierista. Italia: La Nuova Italia, 1991.

Trebbi, Rómulo. "Del jardín de los dioses al parque de los hombres". Parques y jardines de Chile por Andrea Díaz. Santiago: World Color Chile, 
2010: 15-17.

Toro, Felipe. "Una pieza secreta: juegos y juguetes en la narrativa de Adolfo Couve". Revista Chilena de Literatura 83 (2013): 177-195.

Valdés, Adriana: "Adolfo Couve, narrador de lo inquietante". Narrativa Completa por Adolfo Couve. Santiago de Chile: Seix Barral, 2003.

. "Un duende y una novela: sobre una obra de Adolfo Couve". Composición de lugar. Escritos sobre cultura. Santiago de Chile: Universitaria, 1996: 181-184.

-----. "Prólogo". Cuando pienso en mi falta de cabeza (La segunda comedia) por Adolfo Couve. Santiago de Chile: Seix Barral, 2000: 7-30.

Wellek, René. "El concepto de realismo en la investigación literaria".

Conceptos de crítica literaria. Venezuela: Biblioteca de la Universidad Central de Venezuela, 1968: 169-91. 